\title{
ESTUDO ANATŌMICO DA MADEIRA DE Vallesia Glabra (Cav.) Link (APOCYNACEAE)
}

Graciela Inēs Bolzon de Muñiz

Instituto de Tecnologia de la Madeira, Universidade de Santiago del Estero, Argentina.

Josē Newton Cardoso Marchiori

Departamento de Ciências Florestais. Centro de Ciências Rurais. UFSM. Santa Maria, RS.

RESUMO

0 presente trabalho descreve a estrutura anatōmica da ma deira de Valzesia glabra (Cav.) Link, com base em uma amostra proce dente de Santiago del Estero, Argentina. São apresentados dados qua $\underline{n}$ titativos e fotomicrografias de detalhes anatômicos.

A madeira possui porosidade difusa, poros pequenos a mé dios e solitārios, placa de perfuração simples, pontuações intervas culares muito pequenas e ornamentadas, raios heterogêneos, parênqui ma apotraqueal, fibrotraqueōides, e cristais em câmaras, em cēlulas dos parênquimas axial e radial.

\section{SUMMARY}

MUNIZ, G.I.B. de \& MARCHIORI, J.A.C. Anatomical study of the wood of Vallesia glabra (Cav.) Link (Apocynaceae). Ciência e Natu $r a, 10: 123-129$.

The anatomical structure of the wood of Valzesia glabra (Cav.) Link is described, based in one specimen collected in the Argentinian Province of Santiago del Estero. Quantitative data and photomicrographs of certain wood features are presented.

The most important anatomical features of the wood are the diffuse porosity, small to medium solitary pores, simple perforation plates, small and vestured intervascular bordered pits, heterogeneous rays, apotracheal axial parenchyma, fibretracheids, and rhomboid chrystals in chambered cells of rays and axial parenchyma.

INTRODUÇAOO

As regiões āridas e semiāridas da Argentina tem uma inte ressante vegetação xerofítica, que suscita o interesse pelo estudo da estrutura anatómica de suas madeiras. 0 presente trabalho tem 0 objetivo de descrever uma destas espécies.

Vazzesia glabra (Cav.) Link è o ūnico representante do gê nero na Argentina, sendo conhecida localmente como ancoche (DIMITRI, 2). 0 gènero pertence à famỉlia Apocynaceae e compreende cerca de 5 espēcies que se distribuem nas regiões quentes da Amērica, tendo a península da Flörida como limite norte.

A espēcie em estudo ocorre desde o sul do Mëxico e América 
Central até o norte da Argentina. Neste paîs habita principalmente os distritos ocidental e serrano da Provỉncia Fitogeogräfica Chaque nha, desde Jujuy até San Juan, La Rioja e Cordoba (EZCURRA, 4).

As propriedades tōxicas, laxativas e antitērmicas de sua amarga casca são tradicionalmente conhecidas. Apresenta tambēm um alcalóide que atua em certos nervos motores, chamado vallesina, ca paz de provocar a morte por paralização respiratōria. Esta substān cia é muito semelhante à Aspidospermina do quebracho-branco (EZCUR RA, 4).

Valzesia glabra è um arbusto ou arvoreta de 1,5 a $7 \mathrm{~m}$ de altura, de caule glabro, e folhas alternas, lanceoladas, inteiras, persistentes. As flores são brancas, pequenas, dispostas em cimas opositifolias. 0 fruto é uma drupa branca, oboval, de endocarpo le nhoso (MARZOCCA, 7).

A bibliografia anatōmica traz escassas referēncias sobre o gênero. METCALFE \& CHALK (8) citam poros de tamanho médio, exclu sivamente solitārios, parēnquima predominantemente apotraqueal e raios com células eretas, contendo.ocasionalmente cristais.

Para a madeira de ancoche, RECORD \& HESS (10) referem cor castanho-amarelada, textura fina, baixa durabilidade natural e boa trabalhabilidade.

MATERIAL E METODO

0 material em estudo é procedente do Parque Chaquenho Se co da Provincia de Santiago del Estero, noroeste da Argentina.

Das amostras de madeira foram preparados bloquinhos orien tados para a obtenção de secções histolōgicas nos planos transversal, longitudinal tangencial e longitudinal radial. C amolecimento dos mesmos foi realizado por fervura em āgua.

Os cortes foram feitos em micrōtomo de deslizamento, com espessura nominal de $18 \mathrm{\mu m}$. Para o tingimento utilizou-se o método de tripla coloração, com vermelho de acridina, crisoidina e azul de astra (DUJARDIN, 3). As secções foram posteriormente desidratadas em sērie alcoōlica ascendente, diafanizadas em xilol e montadas com "Entellan".

A maceração dos tecidos componentes da madeira foi obtida pelo método de Jeffrey (FREUND, 5). Utilizou-se safranina como co rante e os mesmos processos de desidratação e montagem anteriormen te referidos.

Para a descrição anatômica seguiram-se as recomendações da COPANT (1), com algumas alterações introduzidas por MARCHIORI (6) e MUNIZ (9). Os dados quantitativos são apresentados na Tabela I.

As fotomicrografias foram tomadas com aparelho Carl Zeiss, no Laboratōrio de Anatomia da Madeira da Universidade Federal do Pa ranā. Usou-se filme Kodak Panatomic X, ASA 32. As ampliações foram 
feitas em papel fotogrāfico Kodabromid F-3 brilhante.

TABELA I - DADOS QUANTITATIVOS DA ESTRUTURA ANATÔMICA DA MADEIRA

\begin{tabular}{|c|c|c|c|c|c|}
\hline & CARACTERISTICA ANATŌMICA & $\begin{array}{l}\text { VALOR } \\
\text { MIN. }\end{array}$ & MED IA & $\begin{array}{l}\text { VALOR } \\
\text { MÃX. }\end{array}$ & $\begin{array}{l}\text { DESV IO } \\
\text { PADRAOO }\end{array}$ \\
\hline 1. & Frequência de poros (poros $/ \mathrm{mm}^{2}$ ) & 28,0 & 56,0 & 72,0 & 3,75 \\
\hline & $\emptyset$ tangencial de poros $(\mu \mathrm{m})$ & 20,0 & 106,0 & 170,0 & 19,20 \\
\hline 3. & Espessura parede de poros $(\mu \mathrm{m})$ & 2,2 & 5,2 & 8,7 & 1,48 \\
\hline 4. & Comprimento elementos vasculares $(\mu \mathrm{m})$ & 120,0 & 269,0 & 350,0 & 32,60 \\
\hline 5. & Comprimento de apêndices ( $\mu \mathrm{m})$ & 15,0 & 39,0 & 135,0 & 15,99 \\
\hline & $\emptyset$ pontuações intervasculares ( $\mu \mathrm{m})$ & 1,5 & 3,8 & 5,0 & 0,99 \\
\hline 7. & $\emptyset$ pontuações raio-vasculares $(\mu \mathrm{m})$ & 1,5 & 3,6 & 5,0 & 0,47 \\
\hline 8. & $\emptyset$ pontuações parênquimo-vasculares ( $\mu \mathrm{m})$ & 1,5 & 3,7 & 5,0 & 0,58 \\
\hline & H. células parênquima axial (um) & 200,0 & 345,0 & 540,0 & 28,61 \\
\hline 10. & $\emptyset$ células parênquima axial ( $\mu \mathrm{m})$ & 13,0 & 26,0 & 32,0 & 4,65 \\
\hline 11. & H. parênquima axial (cēlulas) & 2,0 & 4,0 & 8,0 & 0,27 \\
\hline & Freatência de raios (raios $/ \mathrm{mm}$ ) & 7,0 & 9,0 & 11,0 & 0,85 \\
\hline 13. & Altura raios unisseriados $(\mu \mathrm{m})$ & 30,0 & 141,0 & 260,0 & 19,91 \\
\hline 14. & Altura raios unisseriados (células) & 1,0 & 5,0 & 10,0 & 1,55 \\
\hline 15. & Largura raios unisseriados $(\mu \mathrm{m})$ & 17,0 & 22,0 & 29,0 & 3,72 \\
\hline 16. & Altura raios multisseriados $(\mu \mathrm{m})$ & 160,0 & 326,0 & 600,0 & 10,82 \\
\hline 17. & Largura raios multisseriados $(\mu \mathrm{m})$ & 20,0 & 36,0 & 50,0 & 0,75 \\
\hline 18. & Largura raios multisseriados (células) & 2 & 3 & 5 & 0,92 \\
\hline 19. & Altura raios multisseriados (cēlulas) & 6 & 19 & 48 & 11,07 \\
\hline 20. & Comprimento de fibras $(\mu \mathrm{m})$ & 450,0 & 956,0 & 1170,0 & 120,32 \\
\hline 21. & $\emptyset$ total de fibras $(\mu \mathrm{m})$ & 16,5 & 19,3 & 22,5 & 2,21 \\
\hline 22. & Espessura parede de fibras $(\mu \mathrm{m})$ & 1,0 & 1,4 & 2,5 & 0,57 \\
\hline
\end{tabular}

DESCRIÇAO DA MADEIRA

Caracteres gerais e organolépticos

Madeira de cerne e alburno distintos, com alburno estrei to (cerca de $2 \mathrm{~cm}$ ), de cor amarelo-rosācea e cerne castanho amarela do; de textura fina, grã direita, sem brilho, macia, não aromātica e sem sabor característico.

Vasos

Poros invisiveis a olho nū; visiveis sob lente, numerosis s simos $\left(28-56-72 / \mathrm{mm}^{2}\right)$, de secção poligonal (Figura lb), diāmetro pequeno a mēdio (20 - 106 - $170 \mu \mathrm{m})$ e paredes finas $(2,2$ - 5,2 $8,7 \mu \mathrm{m})$. Porosidade difusa, uniforme; poros tipicamente solitārios, raramente geminados (Figura la).

Elementos vasculares muito curtos (120 - $269-350 \mu \mathrm{m})$, com placa de perfuração simples (Figura 2b), e apêndices curtos a lon gos $(15-39-135 \mu \mathrm{m})$, presentes geralmente em ambas extremidades. Espessamentos espiralados ausentes. 

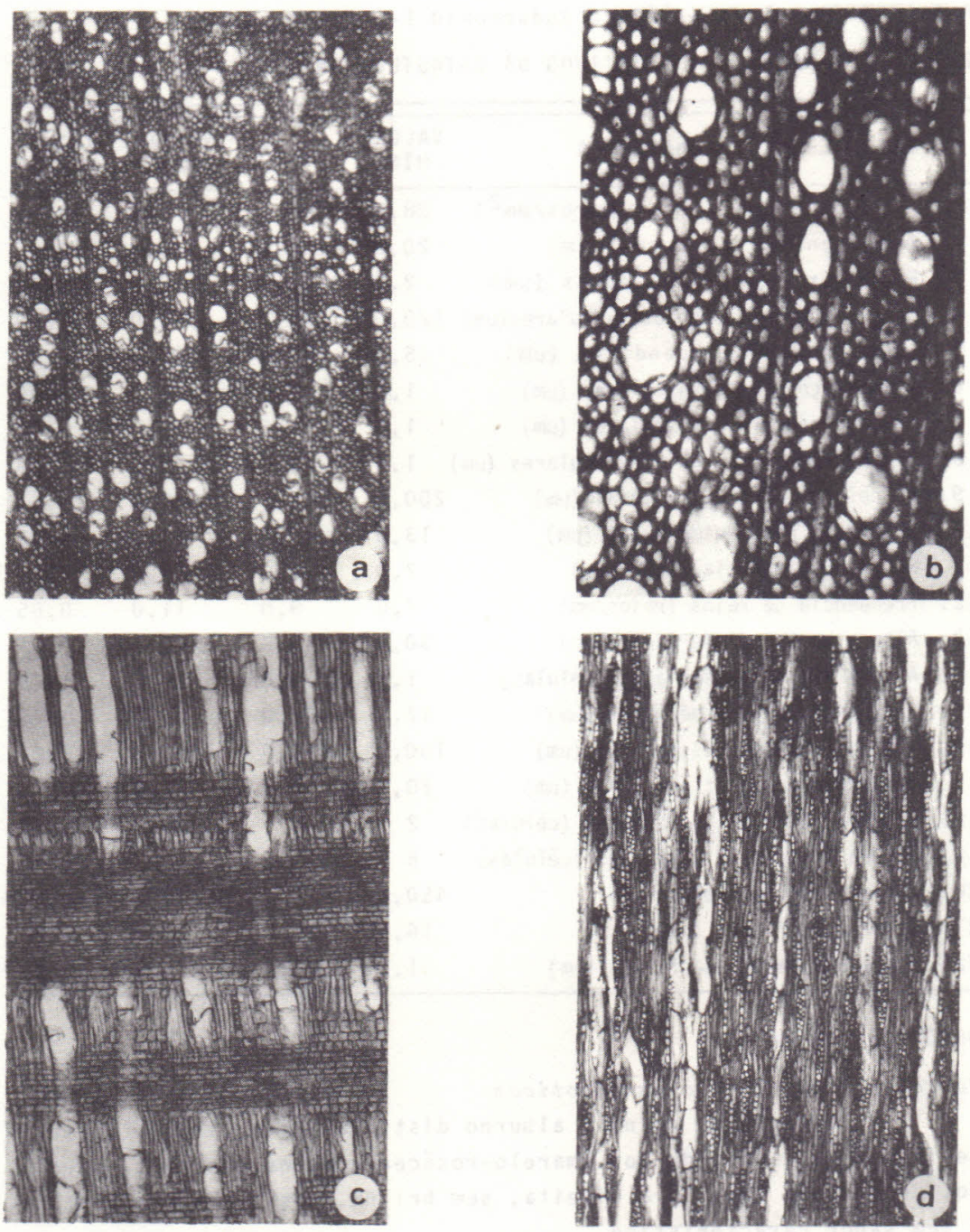

Figura 1 - a) Secção transversal (32 X), mostrando porosidade difu sa e limite de anel de crescimento.

b) Poros de secção poligonal; secção transversal (126 X).

c) Raios heterogêneos, em secção longitudinal radial(32X).

d) Seç̧ão longitudinal tangencial ( $32 \mathrm{X})$.

Pontuações intervasculares de ocorréncia muito escassa de vido à não associação de poros; em arranjo alterno, muito pequenas $(1,5-3,8-5 \mu \mathrm{m})$, ornamentadas, de forma circular, e com abertura lenticular, inclusa, horizontal.

Pontuações raios-vasculares e parênquimo-vasculares muito 
pequenas e arredondadas, semelhantes às intervasculares. Tilos, aú sentes. Conteúdos, não observados em vasos e poros.
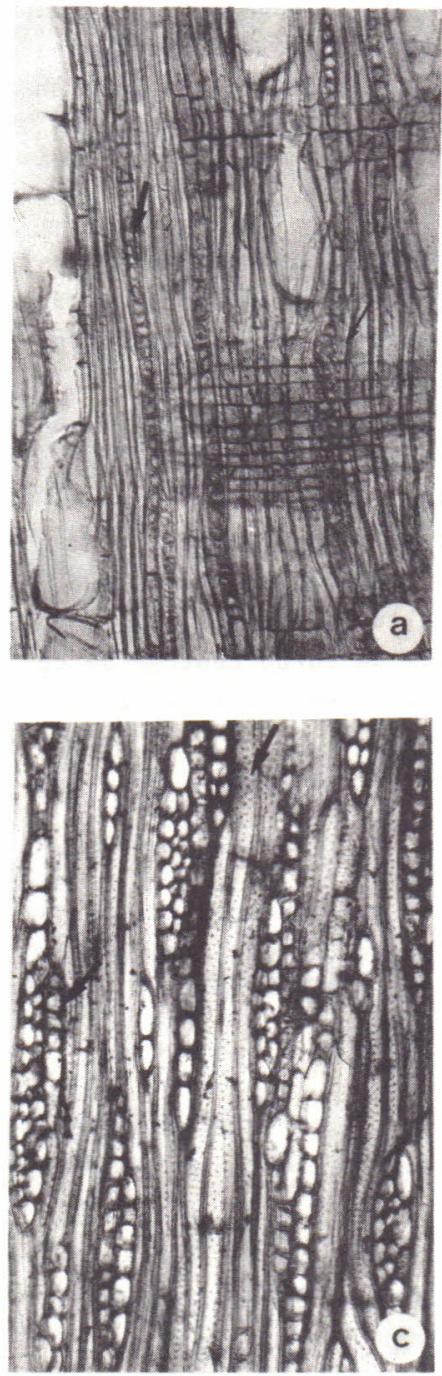
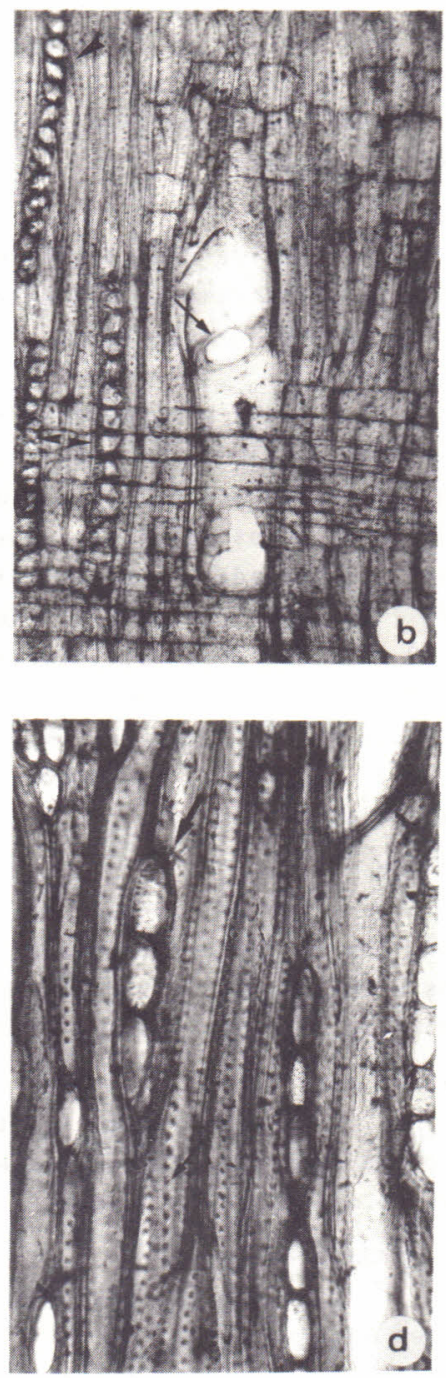

Figura 2 - a) Cristais rombōides em câmaras no parênquima axial (80X).

b) Placa de perfuração simples (secção longitudinal rá dial, $126 \mathrm{X})$.

c) Raio multisseriado e fibrotraqueóides, em secção lon gitudinal tangencial (126 X).

d) Raio unisseriado e pontuações areoladas em fibras (seç ção longitudinal tangencial, $252 \mathrm{X}$ ). 
Parênquima axiaz

Em arranjo apotraqueal difuso e sub-agregado; pouco abun dante. Células de parénquima axial de 200 - 345 - $540 \mu \mathrm{m}$ de altura, por 13 - 26 - $32 \mu \mathrm{m}$ de largura, em sēries axiais não estratificadas com $2-4$ - 8 cēlulas. Cristais romboēdricos e maclas, de ocorrēn cia frequente no parênquima axial (Figura 2a), notadamente nas adja cências de raios.

Raios

Tecido radial heterogêneo (Figura $1 \mathrm{c}$ ): composto por raios uni e multisseriados, não estratificados e de relacionamento predo minantemente normal; raios axialmente fusionados, pouco frequentes (Figura 1d).

Raios unisseriados muito baixos (30 - $141-260 \mu \mathrm{m})$, com 1 - 5 - 10 cēlulas de altura (Figura 2d); muito finos (17 - 22 - 29 $\mu \mathrm{m})$, composto por cēlulas quadradas e eretas.

Raios multisseriados com 2 a 5 cēlulas de largura, e mar gens unisseriadas relativamente curtas (Figura 2C); baixos (160 $326-600 \mu \mathrm{m})$, com 6 - 19 - 48 cēlulas de altura, e finos (20 - 36

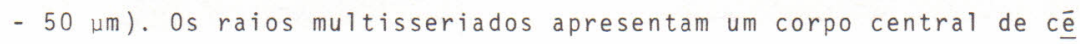
lulas horizontais, com ocasionais cēlulas envolventes, e curtas mar gens de cēlulas quadradas e eretas.

Cristais romboédricos, frequentes em câmaras no parênqui ma radial.

Fibras

Tecido fibroso constituído por fibrotraqueóides não septa dos, com pontuações areoladas conspicuas (Figura 2c, 2d); muito cur tos a curtos $(450-956-1170 \mu \mathrm{m})$, estreitos $(16,5-19,3-22, \overline{5}$ $\mu \mathrm{m})$ e de paredes delgadas $(1,0-1,4-2,5 \mu \mathrm{m})$.

Outros caracteres

Canais secretores, tubos laticíferos e taninïferos, lïber incluso e estratificação, ausentes. Māculas medulares, não observa das no material analisado.

Anéis de crescimento

Distintos, marcados por estreita margem de fibras com pa redes mais espessas.

ANALLISE DA ESTRUTURA ANATŌMICA

Os caracteres anatómicos mais conspicuos na madeira de Vallesia glabra (Cav.) Link, tais como poros pequenos a médios, pla ca de perfuração simples e pontuaçōes intervasculares muito peque nas e ornamentadas, são de ocorrência comum em Apocinaceae, segundo a literatura consultada.

A ocorréncia de poros exclusivamente solitārios é carāter tipico da tribo plumerieae (METCALFE \& CHALK, 8). 
A madeira em estudo apresenta alguns caracteres primiti vos, tais como raios heterogêneos, parênquima axial apotraqueal e fibras com pontuações areoladas. A presença de câmaras cristalîfe ras em cēlulas radiais é pouco comum na famỉlia, sendo citada por METCALFE \& CHALK (8) para apenas 6 gēneros, alēm de valzesia.

Raios com até 4 - 6 cēlulas de largura são pouco frequen tes em Apocynaceae o caräter é referido por RECORD \& HESS (10) para o gênero em estudo, alēm de Rauworfia, Peschiera, Anartia, Bonafou. sia, Tabernaemontana e certas espécies de Aspidosperma.

\section{REFERENCIAS BIBLIOGRAFFICAS}

1. COMISION PANAMERICANA DE NORMAS TECNICAS. 301-019, novembro, 1973.

2. DIMITRI, M.J. Enciclopedia Argentina de Agricultura y Jardine ria. Buenos Aires, Ed. ACME S.A.C.I., 1972. 1028 p.

3. DUJARDIN, E.P. Eine neue Holz-zellulosenfaerbung. Mikrokosmos, 53: $94,1964$.

4. EZCURRA, C. Revision de las Apocināceas de la Argentina. Darwi niana, $23(2-4): 367-474,1981$.

5. FREUND, H. Handbuch der Mikroskopie in der Technik. Frankfurt, Umschan Verlag, 1970. 379 p.

6. MARCHIORI, J.N.C. Estudo anatômico do xilema secunāário e da casca de algumas espécies dos gêneros Acacia e Mimosa, nati vas no Estado do Rio Grande do Sul. Curitiba, 1980. 186 p. Dissertação. Mestrado. Universidade Federal do Paranā. Setor de Ciēncias Agrárias. Curso de Pós-Graduação em Engenharia Florestal.

7. MARZOCCA, A. Apocinaceas. In: Las Plantas cultivadas en la Repu brica Argentina. Buenos Aires, Misc. Min. Agric. y Ganad. 9 (163). 68 p. 1952.

8. METCALFE, C.R. \& CHALK, L. Anatomy of the Dicotyzedons. 0xford, Clarendon Press, 1950. 1500 p.

9. MUNIZ, G.I.B. de. Descrição da estrutura e ultraestrutura da ma deira de cinco espécies de Prosopis da Argentina e análise da metodologia. Curitiba, 1986. 192 p. Dissertação. Mestrado. Universidade Federal do Paranā. Setor de Ciēncias Agrārias. Curso de Pōs-Graduação em Engenharia Florestal.

10. RECORD, S.J. \& HESS, R.W. Timbers of the New World. New Haven, Yale University Press, 1949. $640 \mathrm{p}$.

Recebido em junho, 1988; aceito em agosto, 1988. 
$$
\text { . }
$$ 